\title{
OS PERSONAGENS DE MARCELINO FREIRE: uma leitura a partir da sociologia da
} literatura

\author{
Guilherme Figueiredo Benzaquen ${ }^{1}$
}

\section{Resumo:}

Esse artigo se insere no campo da sociologia da literatura para fazer uma análise do livro Contos negreiros do escritor pernambucano Marcelino Freire. A questão central que nos guiará será: o que nos revelam os personagens de Freire? Para respondê-la, iremos articular uma análise dos aspectos intrínsecos e extrínsecos à obra, entendendo-os em uma relação dialética. Quanto ao seu estilo, será fundamental trabalhar criticamente a oralidade e o minimalismo. Sobre os temas, acreditamos ser necessário abordar, por suas recorrências, a violência, o racismo e a homossexualidade. Recorreremos a diferentes autores para fundamentarmos nossa análise, porém nos servirá de eixo central a teoria de Candido do personagem e a noção de testemunho. Procuraremos, a partir desse duplo enfoque, fornecer uma contribuição para a discussão, central na sociologia da literatura, acerca dos limites entre a ficção e a realidade.

Palavras-chave: Marcelino Freire, Personagens, Antônio Candido, Testemunho, Contos negreiros

\begin{abstract}
:
This article is an effort of sociology of literature to make an analysis of the book Contos negreiros by Marcelino Freire. The central question that will guide us will be: what do the characters of Freire reveal to us? To answer it, we will articulate an analysis of the intrinsic and extrinsic aspects of the book, understanding them in a dialectical relation. As for the style, it will be critical to work with orality and minimalism. On the themes, we believe that violence, racism and homosexuality need to be addressed because of their recurrences. We will go to different authors to base our analysis, but will serve as the central axis Candido's theory of the character and the notion of testimony. We will seek, from this double focus, to contribute to the discussion, central in the sociology of literature, about the limits between fiction and reality.
\end{abstract}

Keywords: Marcelino Freire, Characters, Antônio Candido, Testimony, Contos negreiros

\footnotetext{
${ }^{1}$ Doutorando em Sociologia pela Universidade Federal de Pernambuco e membro do grupo de pesquisa Sociedade Brasileira Contemporânea: Cultura, Democracia e Pensamento Social, vinculado ao Programa de Pósgraduação em Sociologia da UFPE. E-mail: benzaqueguilherme@gmail.com
} 
"Escrevo para me vingar, nessa luta eterna entre oprimidos e opressores."

(Marcelino Freire).

\section{Introdução}

Marcelino Freire é um escritor do nosso tempo e do nosso lugar. Os eventos que narra são próximos, são histórias que poderiam nos ter sido contadas em uma viagem de ônibus. Porém, o seu mérito está na maestria com que ele as transforma em escrita e, dessa maneira, acaba por nos abrir os olhos para aquilo que nos rodeia, que sempre esteve ali. Negros, gays, trabalhadores, prostitutas, crianças, estrangeiros são personagens de contos que quase sempre estão lidando com temas que ao mesmo tempo são cotidianos para uns e invisibilizados para todos aqueles que não o vivem diretamente. Ele passeia com habilidade entre esses dois campos fazendo do invisível visível. Esse esforço não é gratuito, é importante porque a produção de ausências serve para legitimar a realidade como única possível. Ir atrás do que é produzido cotidianamente como "não-existente" é se contrapor ao hegemônico (SANTOS, 2002).

Falando sobre as desigualdades sociais, Freire escreve sem comiseração pelos seus personagens. Em suas histórias, eles próprios se narram como objetos de vidas que muitas vezes chocam por um excesso de humanidade. O humor é muitas vezes um recurso, não para diminuir os personagens, mas para rirmos com eles das desgraças que vivem. Em um tom realista, o autor está sempre lidando com a opressão. Colocar nossos rostos na frente dessas realidades revela sua posição de intermediário entre esses sujeitos e as nossas vivências particulares.

A nossa análise se centrará no livro Contos negreiros lançado em 2005 e ganhador do Prêmio Jabuti de Literatura. A questão central que nos guiará será: o que nos revelam os personagens de Freire? Para respondê-la, iremos casar uma análise dos aspectos intrínsecos e extrínsecos à obra, entendendo-os em uma relação dialética. Quanto ao seu estilo, será fundamental trabalhar criticamente a oralidade e o minimalismo, duas características recorrentes de sua obra. Sobre os temas, acreditamos ser necessário abordar, por suas recorrências, a violência, o racismo e a homossexualidade. Após essa introdução, começaremos nossa análise com uma breve contextualização sobre Marcelino Freire e o livro analisado. Depois passaremos para uma caracterização dos personagens e das temáticas que eles nos revelam. 
Recorreremos a diferentes autores para fundamentarmos nossa análise, porém nos servirá de eixo central a teoria do personagem, de Candido, e a noção de testemunho. Os personagens serão tratados como seres fictícios que têm como função privilegiada a de nos gerar empatia na literatura. Candido é um autor que problematizou de forma bastante produtiva os limites entre ficção e realidade, o que o torna uma referência importante para esse trabalho que se insere no campo da sociologia da literatura. Quanto ao debate sobre testemunho, essa é uma abordagem específica da produção literária que tem por objetivo problematizar a relação entre a linguagem e o real através do enfoque da literatura como um relato de sobrevivência de situações limites. Freire tem como uma de suas características principais esse tensionamento para revelar as misérias dos seres humanos. Procuraremos, a partir desse duplo enfoque, fornecer uma contribuição para a discussão, central na sociologia da literatura, acerca dos limites entre a ficção e a realidade. Partiremos de uma constatação proveniente da noção de testemunho de que, ao se contrapor ao positivismo (que quer dar conta do real) e ao relativismo (que elimina o real), é necessário pensar "o real a partir de uma participação/imersão ativa dos sujeitos de conhecimento no processo histórico" (SELIGMANN, 2003, p. 10). Essa será nossa posição enquanto pesquisador e é a posição de Freire que parece entender a autoria como o assumir uma responsabilidade frente aos processos do mundo. Os seus personagens não são meras ilustrações das ideias que os perpassam, mas sim agentes que tentam problematizar e transformar essas ideias.

\section{Quem é Marcelino Freire?}

Freire é um expoente da literatura contemporânea brasileira. Nascido em Sertânia no interior de Pernambuco, ele foi o caçula de nove filhos. Em toda sua infância existia uma demanda por uma determinada manifestação da masculinidade ligada à realização de atividades físicas, que não era suprida. A criança Marcelino estava mais ligada aos trabalhos intelectuais. Ele relata que teve uma infância de reclusão entre livros e que fez teatro por dez anos. Aqui começamos a ver as práticas cotidianas que iriam formar o escritor Freire anos depois. A família saiu de Sertânia e seguiu para Paulo Afonso. Porém, mais decisiva foi a fase que viveu em Recife e que durou dos 8 aos 24 anos (GRUNNAGEL; WIESER, 2015). A importância desse tempo fica clara ao percebermos que a presença do universo recifense em sua obra é marcante, sendo comum que suas histórias se passem na capital pernambucana. Em 1991, se mudou para São Paulo, onde vive até hoje. Publicou ao todo 7 livros, 5 deles de 
contos, além de participar em inúmeras coletâneas.

Freire se insere naqueles que trabalham a desigualdade como tema literário. No quadro da produção atual ele busca se aproximar do que é conhecido como literatura marginal. Em uma entrevista, o autor afirma que não se identifica com o regionalismo, mas sim com a literatura produzida por Ferréz, um dos representantes mais conhecidos dessa corrente (FREIRE in GRUNNAGEL; WIESER, 2015). O termo literatura marginal tende a englobar autores que são marginais não apenas na temática, mas também em suas origens sociais: são, em sua maioria, moradores da periferia e que lidam de forma direta com contextos violentos. "Há na atual Literatura Marginal o declarado cuidado de denunciar os desmantelos da sociedade e promover a conscientização dos direitos sociais que deveriam atender a todos" (FERRAZ, 2009, p. 32). Em termos estilísticos, a oralidade é valorizada por refletir melhor a vivência dos marginalizados. Partindo de contextos de opressão capitalista, Freire parece querer falar para um público de intelectuais de classe média. São esses que devem ver essas realidades algumas vezes distantes para eles.

Aqui a noção de testemonio é interessante para entendermos essa ponte realizada pelo autor. Esse conceito de origem latino-americana surgiu na década de 1980. O testemunho como relato dos outros remete à ideia de que os escritores sempre escrevem criticamente a partir e sobre a comunidade em que estão inseridos. Porém, essas são muitas vezes transcrições porque o autor é um indivíduo letrado que domina as formas de narrar e retrata realidades daqueles que não utilizam a escrita como forma de testemunho de suas vidas. $\mathrm{O}$ autor tem, portanto, que lidar com o problema que é pensar como criar a narrativa sem realizar a domesticação do outro (SELLIGMAN, 2003).

\section{Cantos negreiros}

O livro Contos negreiros é composto por 16 cantos. Há em Freire uma busca constante de tensionamento das estruturas formais, por isso os contos são chamados de cantos. Esse nome tem relação com a valorização da oralidade na prosa do livro. Em uma escrita ritmada e muito próxima da fala oral, o efeito atingido por Freire é o de nos aproximar desses personagens cotidianos. São pessoas que falam muitas vezes em tom de desabafo (LIMA, 2007). A fluidez do livro nos remete a cantos que deveriam ser lidos em voz alta para melhor percebermos a melodia do texto. No segundo canto temos um exemplo dessa proposta do autor: 
“a graça era ninguém ser avisado. Perde-se a espontaneidade do depoimento. O condômino falar como é viver com carros na garagem, saldo, piscina, computador interligado. Dinheiro e sucesso. Festival de Brasília. Festival de Gramado. A gente fazendo exibição no teatro da escola, no salão de festas do prédio" (FREIRE, 2005, p.25).

Geralmente, a repetição da sílaba "ado" seria evitada para não incorrer no vício de linguagem do eco. Porém, é justamente essa repetição que nos remete a como as pessoas falam no cotidiano e que nos faz entrar em um determinado ritmo de leitura que nos leva a acentuar o final das frases.

O tensionamento da forma gênero também fica explícito no primeiro dos cantos do livro, Trabalhadores do Brasil, que nos remete a uma lamentação, a uma espécie de oração. Os personagens têm nomes de divindades ou heróis históricos da cultura negra, porém são apresentados como trabalhadores explorados pelo sistema capitalista. Não há uma narrativa nos moldes tradicionais de uma história a ser contada com eventos e um desfecho. O conto aqui se transforma em algo diferente do que era produzido por autores clássicos como Guy de Maupassant. Somos apresentados a uma determinada situação de exploração através de um canto de lamúria e no final há uma frase bastante forte, vinda da boca de um negro: ninguém é escravo de ninguém. $\mathrm{O}$ que demonstra uma ironia relativa ao quanto há de escravidão em nossas vidas cotidianas e como os postos mais degradantes do mercado de trabalho ainda são preenchidos pelos negros.

Tanto essa quanto as outras narrativas são bem curtas e esse minimalismo faz com que tenham uma força explosiva bastante concentrada. Se o conto já é um gênero marcado pela densidade, Freire faz um esforço de aumentá-la ainda mais, eliminando do texto tudo aquilo que poderia ser supérfluo. Em apenas algumas linhas somos apresentados a situações agoniantes que geralmente não têm uma solução clara. $\mathrm{O}$ minimalismo também se faz presente na escassez de descrições dos personagens e dos cenários. Isso contradiz uma tendência constatada por Candido (2007, p. 79), “os romancistas do século XVIII aprenderam que a noção de realidade se reforça pela descrição de pormenores, e nós sabemos que, de fato, o detalhe sensível é um elemento poderoso de convicção". Esse movimento não é feito apenas por Freire como é possível constatar ao percebermos o quanto está se proliferando a produção de micro, mini e nanocontos. Porém, mesmo sem um uso extensivo de detalhes, somos capazes de visualizar perfeitamente as situações criadas pelo autor, provavelmente pelo caráter violento e cotidiano delas. Há muito de visual na narrativa de Freire, muito de dramatúrgico, como fica provado pelo fato de alguns dos seus livros terem sido transformados 
em peças (o caso de Angu de Sangue, Rasif e Nossos Ossos, todos encenados pelo coletivo teatral pernanbucano Angu).

Nesse livro há também um questionamento da norma considerada culta, o que o transforma em um exemplo da problematização que Eagleton (2006) faz da definição de literatura do formalismo russo. Para eles, a literatura deveria ser pensada como um emprego peculiar da linguagem, pois tinham como preocupação central a realidade material do texto literário em si. Essa corrente de crítica era a aplicação da linguística formal ao estudo da literatura. Mais do que o conteúdo, o que se buscava era a análise da literatura como fato material, de maneira que o texto deveria ser analisado de forma parecida com a de uma máquina. A linguagem da literatura deveria ser aquela extremamente trabalhada. Freire com certeza trabalha a linguagem de forma bastante intensa, porém o problema principal desse tipo de definição é que se a literatura é um desvio na linguagem é necessário encontrar a norma, tarefa impossível de ser realizada por conta das variações histórico sociais. Aquilo que os cânones da literatura mundial fizeram com a literatura é muito diferente do que Freire faz, portanto é necessário entender que não é apenas a partir de uma definição formal que poderemos definir o que é ou não literatura. A solução de Eagleton é historicizar a definição da literatura, a caracterizando como uma determinada relação das pessoas com a escrita. "Não existe uma essência da literatura" (EAGLETON, 2006, p. 12), seria, portanto, um tipo de escrita que, por alguma razão, é altamente valorizado. Se for o valorizado, é mutável porque os valores mudam e Freire é uma das forças atuando nessa mudança. Ele leva a literatura nacional a caminhos da oralidade e da melodia que poucas vezes são vistos serem trabalhados da mesma maneira.

Para finalizar essa caracterização do livro é importante ressaltar que Contos negreiros é uma obra que se passa no presente e no Brasil. São muitas as referências que nos permite localizar o tempo e o espaço. Os cenários mais recorrentes são Pernambuco e Rio de Janeiro, porém também somos levados à Bahia e à Amazônia. No último caso, há um relato bastante impactante de turismo sexual de um estrangeiro que se apaixona por uma criança indígena chamada Yamami. Esse que é um dos cantos mais fortes do livro, nos revela o quanto há de exploração nesse rincão misterioso e pouco noticiado do nosso país. O estrangeiro não quer saber da paisagem, não quer conhecer o Brasil, pois “o Brasil é São Paulo”. Ele quer é oprimir uma criança dando como justificativa a sua paixão. Somos confrontados com uma moral que pouco percebe as consequências de suas ações sobre os outros. A angústia quando terminamos 
o conto e, por conseguinte o livro já que é o último, é: quantas Yamamis estão sendo exploradas agora mesmo? Nosso território e nosso presente são transformados em cenário e em alvo das problematizações. Essa é a temática central do livro: a opressão em uma sociedade extremamente desigual. E nesse sentido, Freire não se furta a sua própria responsabilidade como opressor.

\begin{abstract}
Desde a capa do livro, que contém a foto de um escravo brasileiro no século XIX, com um código de barras ocultando o órgão sexual dele, eu estou de alguma forma dizendo 'Você, que está levando esse livro, vai ter que saber quanto é o livro e quanto é o negro que você está levando para casa'. O meu receio de ter feito um livro como esse era de eu me colocar acima, como um branco querendo entender os problemas do Brasil e também que o livro viesse a se tornar um "discurso" de ONG. É por isso que eu me coloco também como opressor (FREIRE in GRUNNAGEL; WEISER, 2015, p. 460).
\end{abstract}

\title{
As pessoas de Freire
}

Os três elementos centrais de uma novela são: personagens, enredo e ideias (CANDIDO, 2007). Os dois primeiros estão relacionados com sua matéria, enquanto que o último representa seu significado. Apesar dessa divisão didática, estão todos intimamente ligados quando a escrita é bem trabalhada. $\mathrm{O}$ que significa que ao analisarmos os personagens de Freire falaremos de seus enredos e de suas ideias. Os personagens vivem no enredo e são o meio pelo qual as ideias são transmitidas. Neles está a possibilidade de adesão afetiva e intelectual. Desde o primeiro momento, os leitores críticos das dominações capitalistas são levados a ter empatia e se identificarem com os marginais de Freire por representarem tipos revoltados e revolucionários. É difícil não desejarmos uma vida melhor para Vanicleia, uma ex-prostituta que tem um marido abusador. No quinto canto, intitulado com o nome da personagem, ela relembra os tempos de prostituição como melhores do que o tempo atual em que é maltratada diariamente. Mais do que uma valorização da prostituição, pois percebemos o quanto há de fantasia ilusória na idealização de Vanicléia, nesse conto fica claro o quanto os relacionamentos entre homens e mulheres têm de violência. Aqui temos o enredo sendo vivido por uma personagem e uma ideia clara que o autor pretendia nos passar. Nossa empatia com ela demonstra que naqueles que sofrem vemos muito do sofrimento cotidiano e sentimos a necessidade da mudança, personagens são, portanto, o vínculo de verdade do leitor com a obra (CANDIDO, 2007).

Isso revela um paradoxo presente na criação literária: a verossimilhança depende de um ser fictício, ou seja, uma criação da fantasia deve nos dar a impressão de uma verdade 
existencial. Candido (2007) demonstra que a solução desse paradoxo está no próprio funcionamento da narrativa. Há diferenças e afinidades entre os seres vivos e os entes de ficção. Lidando com as pessoas a nossa volta, temos a percepção de que há uma imprevisibilidade nos seres que está relacionada a nossa incapacidade de apreender o interior desses indivíduos, suas personalidades. Esse "mistério dos seres" foi investigado sistematicamente pela literatura do século XIX. "O romance, ao abordar as personagens de modo fragmentário, nada mais faz do que retomar, no plano da técnica de caracterização, a maneira fragmentária, insatisfatória, incompleta, com que elaboramos o conhecimento dos nossos semelhantes" (CANDIDO, 2007, p. 58). A diferença é que no romance isso é criado pelo escritor e quando é criação o personagem é mais coeso e lógico do que as pessoas, mesmo que o escritor queira torná-lo incoerente. Quando o romancista caracteriza seus personagens pode ser sua intenção dar a impressão de um ser ilimitado e contraditório, porém o leitor apreende enquanto um ser coeso ante sua imaginação. É verdade que nos últimos séculos houve um aumento na complexidade da psicologia dos personagens, chegando à possibilidade de várias distinções analíticas. Uma delas foi a criada entre o personagem de costume (invariável e com caracterização externa) e o personagem de natureza (irregular e com um complexo modo íntimo de ser). Outra possível é a que distingue entre personagens planas e esféricas, onde a diferença está na capacidade da personagem supreender o leitor. A conclusão dessa relação do leitor com a personagem, ou seja, do problema da verossimilhança é que uma das funções capitais da ficção é nos dar um conhecimento mais completo do quão fragmentário somos. A arte seria, dessa maneira, a única que nos daria a certeza do interior dos seres, mesmo que de forma limitada. Daí nossa empatia por esses seres que nem mesmo "existem".

Outro aspecto que nos faz apreender as obras ficcionais como verossímeis é a coerência interna da narrativa. A verdade da personagem "depende, antes do mais, da função que exerce na estrutura do romance, de modo a concluirmos que é mais um problema de organização interna que de equivalência à realidade exterior" (CANDIDO, 2007, p. 75). A verossimilhança está relacionada com essa capacidade de estabelecer uma coerência interna. Nem sempre o que nos parece inverossímel na realidade vai ser assim interpretado em uma leitura, pois os eventos e descrições podem estar coerentes com a estrutura narrativa, o que nos dará uma impressão de verdade. O que leva à conclusão de que um dos pontos fundamentais do trabalho de um escritor é a organização do contexto em que se passa a sua 
narrativa. Na obra de Freire encontramos um exemplo dessa argumentação no sexto canto, intitulado Linha do Tiro, provavelmente uma referência a uma linha homônima de ônibus que circula por Recife. Uma senhora e um assaltante de um ônibus interagem em um loop eterno: ela não entende muito bem a situação, o que faz com que o assalto não consiga se concretizar. O assaltante tenta fazer com que ela entenda o que está acontecendo, mas ela se confunde (ou finge se confundir para proteger-se) e pensa ser uma conversa, uma tentativa de venda e um alerta sobre outro assalto. A inovação formal é clara e se dá na repetição ad infinitum de um mesmo diálogo. Em uma situação "real" seria inverossímel que as mesmas palavras fossem ditas por duas pessoas numa repetição eterna, porém dentro do contexto do conto essa repetição parece plausível, embora risível. Temos consciência que se trata de um relato ficcional, porém não questionamos o status de verdade dos personagens.

Começamos a entender que "a personagem é, basicamente, uma composição verbal, uma síntese de palavras, sugerindo certo tipo de realidade" (CANDIDO, 2007, p. 78). O que nos leva ao problema do quanto os personagens são reproduções de pessoas existentes ou invenções da cabeça do autor. Recorrendo a Candido, podemos responder essa questão através de uma definição onde existem dois polos impossíveis da criação do personagem: em um ele é a transposição fiel de modelos reais e no outro é uma invenção completamente imaginária. Candido cita uma série de formas possíveis de criação que são variações entre esses dois polos. A sua conclusão é que independente como se dê a configuração em um determinado autor, a criação é sempre "um trabalho criador, em que a memória, a observação e a imaginação se combinam em graus variáveis, sob a égide das concepções intelectuais e morais" (CANDIDO, 2007, p. 74). O romancista não é capaz de reproduzir a vida e se assim fosse não estaria realizando literatura, pois para escrever é necessário selecionar, dar uma certa ordem e conduzir a narrativa de uma forma coesa que não é a maneira como a vida se dá. Mesmo quando toma um modelo na realidade, os personagens sempre têm algo de imaginário, de construção psicológica que permite que existam como seres ficcionais. Porém, do outro lado, qualquer invenção deve ter algum rastro de realidade, pois nada se cria do vácuo. Essa constatação é importante para a sociologia da literatura e para a discussão que realizamos nesse artigo porque é mais uma defesa da tensão que existe entre o real e o ficcional. Dado que os personagens - e podemos estender esse argumento para toda a literatura - têm sempre algum rastro de observação do real, a literatura não é apenas um objeto a ser analisado para compreendermos a sociedade, mas também um discurso sobre essa 
realidade. Por mais que utilize métodos muito alheios aos da ciência, a literatura é uma construção de conhecimento acerca dos processos que os escritores vivem e como tal deve ser valorizada.

Entendidos dessa maneira, quem são esses personagens em Contos negreiros? São moradores de favelas, nordestinos imigrantes, trabalhadores, estrangeiros (turistas sexuais), prostitutas, velhas, assaltantes, mães e crianças. De alguma forma carregam em si a marca do insucesso ou do desvio. Quando não, como no caso de dois cantos sobre turismo sexual, são os agentes da opressão e são retratados como seres cruéis. No quarto canto, Alemães vão à guerra, um estrangeiro tenta convencer seu amigo Johann a procurar negras no Brasil. O estrangeiro que vem fazer turismo sexual é um personagem constante da obra de Freire. Em termos estilísticos, o português cheio de erros de pronúncia é reproduzido na escrita, o que faz com que a caracterização do personagem se aproxime muito da imagem que temos dos "gringos". O turismo sexual, apesar de condenado moral e juridicamente, é uma prática da elite financeira, o que coloca o gringo em um patamar superior ao da mulher negra que está na condição de objeto sexual. Porém é um personagem desviante e que carrega em si as marcas dos temas centrais de Freire: a opressão e a desigualdade social.

De modo geral, entretanto, os dois tipos sociais mais presentes nos contos são os negros e os gays: ambos sujeitos ao processo de gritante desigualdade do nosso país. Esses são grupos sociais que interagem de forma desigual com a distribuição escassa de bens, de acesso à educação, aos postos de trabalho, sempre tendo que lidar com algum grau de desvantagem quando comparados com os homens brancos heterossexuais. Porém, ao contrário do que acontece em outras literaturas, o negro não é na obra de Freire um figurante que serve para dar verossimilhança à narrativa (LIMA, 2007). Ele é um agente central dos seus processos, mesmo quando percebemos as opressões estruturais que o condicionam a viver contextos que não são os que desejariam. Esse é o caso do terceiro canto, Esquece, quando um assaltante, um pai de família, enfim um negro tenta (ou projeta) um assalto frustrado. Percebemos em seus pensamentos que o assalto não é seu objeto de desejo, mas sim uma vida mais digna. Porém não estamos frente a uma narrativa moralista, pois Freire retrata que o assalto, por mais que indesejado, pode sim ser um caminho legítimo para a obtenção de alguma melhora de vida frente a tanta violência cotidiana. Nesse assalto, que pode ser apenas uma projeção, está demarcada a questão: o que é a violência? É o assalto ou toda a opressão cotidiana que está institucionalizada no capitalismo? 
Devemos voltar para a noção de testemunho porque ela nos ajuda a compreender a realidade desses personagens marginalizados. $\mathrm{O}$ testemunho é um interlocutor de realidades extremas, de temas limites. No Brasil, os negros e homossexuais são exemplos de indivíduos que vivem essas situações. Porém, para além de uma mera descrição dessas realidades, o testemunho tem um papel ativo de busca de reestituição do que é traumático, de busca de uma superação dessas realidades extremas. Nesse sentido, o testemunho tem uma relação ambígua com a palavra, pois ao mesmo tempo em que tenta narrar percebe os limites dessa narração. Percebe quão difícil é lidar com esses temas limites dando a eles toda a intensidade que têm no plano do real. A volta para o evento traumático na narrativa é uma tentativa de catarse e superação do evento traumático. O que torna possível afirmar que a palavra testemunho está ligada à noção de denúncia social (FERRAZ, 2009).

Nas escritas próximas à ideia de testemunho é comum a valorização do particular porque o universal não pode dar conta do real. Geralmente se fala de uma pessoa exemplar que vale para toda a comunidade. Esse é o caso de Freire, onde os personagens individuais representam problemas coletivos. Algumas vezes eles não têm nomes e, em sua maioria, as características físicas não estão bastante claras, porém, ainda assim podemos identificar um certo tipo de pessoas que existe na sociedade e que lida com problemas semelhantes. No décimo canto, Nossa rainha, vemos a relação de uma mãe com uma criança que sonha em ser Xuxa. O problema é que o sonho é impossível para uma menina da favela, provavelmente negra, e a mãe tem que lidar com essa frustração vindoura. A mãe relata sua agonia e seus sacrifícios para realizar o desejo da filha de ver a "rainha dos baixinhos". Nesse relato vemos claramente as crianças pobres que têm que lidar cotidianamente com as limitações que lhe são impostas ao mesmo tempo em que são estimuladas a sonhos irrealizáveis. Do outro lado vemos também as mães que se sacrificam para além do que poderiam por não terem acesso às possibilidades que tornariam a vida dos filhos mais realizadas. Esse é um personagem pelo qual temos empatia, pois reconhecemos o sofrimento e, nos seus xingamentos, vemos uma maneira muito humana de reagir aos nossos desafios diários.

\section{Considerações finais: o que os personagens revelam}

Para concluirmos nosso artigo faremos uma breve sistematização das ideias que os personagens de Marcelino Freire nos transmitem, nos fazem sentir. Podemos englobar as suas preocupações temáticas em três grandes grupos: a violência, a sexualidade e a raça. Como 
defendemos anteriormente, o grande tema de Freire é a desigualdade social e, a partir dele, podemos dizer que ele se preocupa com os afetados por essa desigualdade (quando trata dos homossexuais e dos negros) e com a forma como essa desigualdade se concretiza na nossa sociedade (quando trata da violência).

O negro aparece na obra de Freire não apenas como personagem, mas como temática e como estrutura narrativa. Há um uso extensivo de referenciais negros, estamos sempre sendo remetidos a nomes e símbolos da cultura afro-brasileira. Esse é um artifício que nos faz pensar na condição do negro na nossa sociedade, ou seja, de marginalização, porém de resistência à submissão. Se o negro sofre uma dupla discriminação por ser pobre e por sofrer preconceito racial, ele não é apenas uma vítima, pois se ergue para exigir uma vida digna. Ele consegue retratar as vivências da negritude, desafiando a ideia de um negro meramente passivo. Há no livro também a figura do negro erotizado, do negro como corpo desejado, que geralmente está relacionado com um desejo homossexual. O que nos remete à questão da homossexualidade, uma presença constante em todos os livros de Freire. Para se contrapor ao discurso heteronormativo, Freire utiliza como estratégia uma exposição da sexualidade homossexual que demonstra o quanto qualquer maneira de amor vale a pena e o quanto os sofrimentos do coração se assemelham. Esse é o caso do oitavo canto, Coração, no qual um homossexual relata sua frustração com um amor não correspondido. Nele o que é comumente estigmatizado como desvio, ser homossexual, revela a sua normalidade com um relato da dor da rejeição que é conhecido por todos que já viveram essa situação.

Por fim, vale retomar uma fala do próprio Freire para pensarmos a questão da violência: "eu não digo que escrevo sobre violência, eu digo que escrevo sob violência" (FREIRE in GRUNNAGEL; WEISER, 2015, p. 458). A violência é parte constituinte do discurso do autor, mais do que um conteúdo, faz também parte da forma. Ele se aproxima de uma parte da literatura contemporânea que tenta lidar com os sentimentos de desorientação e insegurança típicos dos nossos tempos. Para isso ele descreve atos violentos, porém também incorpora a violência no discurso dos personagens, nas caracterizações e nas palavras escolhidas para narrar. Marcelino Freire e seus personagens se apresentam não apenas para denunciar realidades inaceitáveis, mas também para transformar essas realidades. E se tiver que ser de forma violenta, será.

\section{Referências bibliográficas}

CANDIDO, A. “A Personagem do Romance". In: A personagem de ficção. São Paulo: Perspectiva, 2007, p.51-80 
EAGLETON, T. "Introdução: o que é literatura?” In: Teoria da Literatura: uma introdução. São Paulo: Martins Fontes, 2006, p. 1-24.

FERRAZ, F. Testemunho e oralidade nos contos de Marcelino Freire: um olhar além da violência. Terra Roxa e outras terras, Londrina, vol. 45, jun. 2009, p.28-35.

FREIRE, M. Contos negreiros. Rio de Janeiro: Record, 2005.

GRUNNAGEL, C.; WIESER, D. “'Sou um homossexual não praticante': entrevista com Marcelino Freire". Estudos de literatura brasileira contemporânea, Brasília, n45, jan/jun. 2015, p.445-462.

LIMA, F. J. R. "Cantos e cantares em Contos negreiros, de Marcelino Freire". Via Atlântica, São Paulo, n12, dez. 2007, p.157-166.

SANTOS, B. de S. "Para uma sociologia das ausências e uma sociologia das emergências". Revista Crítica de Ciências Sociais, Coimbra, n63, 2002, p. 237-280.

SELIGMANN-SILVA, M. "Introdução". In: SELIGMANN-SILVA, M (Org.). História, Memória, Literatura: O Testemunho na Era das Catástrofes. Campinas: UNICAMP, 2003. p.7-44.

Recebido em: Julho de 2017 Aprovado em: Dezembro de 2017 